\title{
Gastric Cancer from a Hyperplastic Polyp on an Endoscopic Submucosal Dissection Scar
}

\author{
Makoto Sono ${ }^{1,2}$, Akihisa Fukuda ${ }^{1}$, Hiroshi Seno ${ }^{1}$ and Shujiro Yazumi ${ }^{2}$ \\ Key words: hyperplastic polyp, adenocarcinoma, gastric cancer, endoscopic submucosal dissection (ESD), \\ ESD scar
}

(Intern Med 58: 1179-1180, 2019)

(DOI: 10.2169/internalmedicine.1636-18)
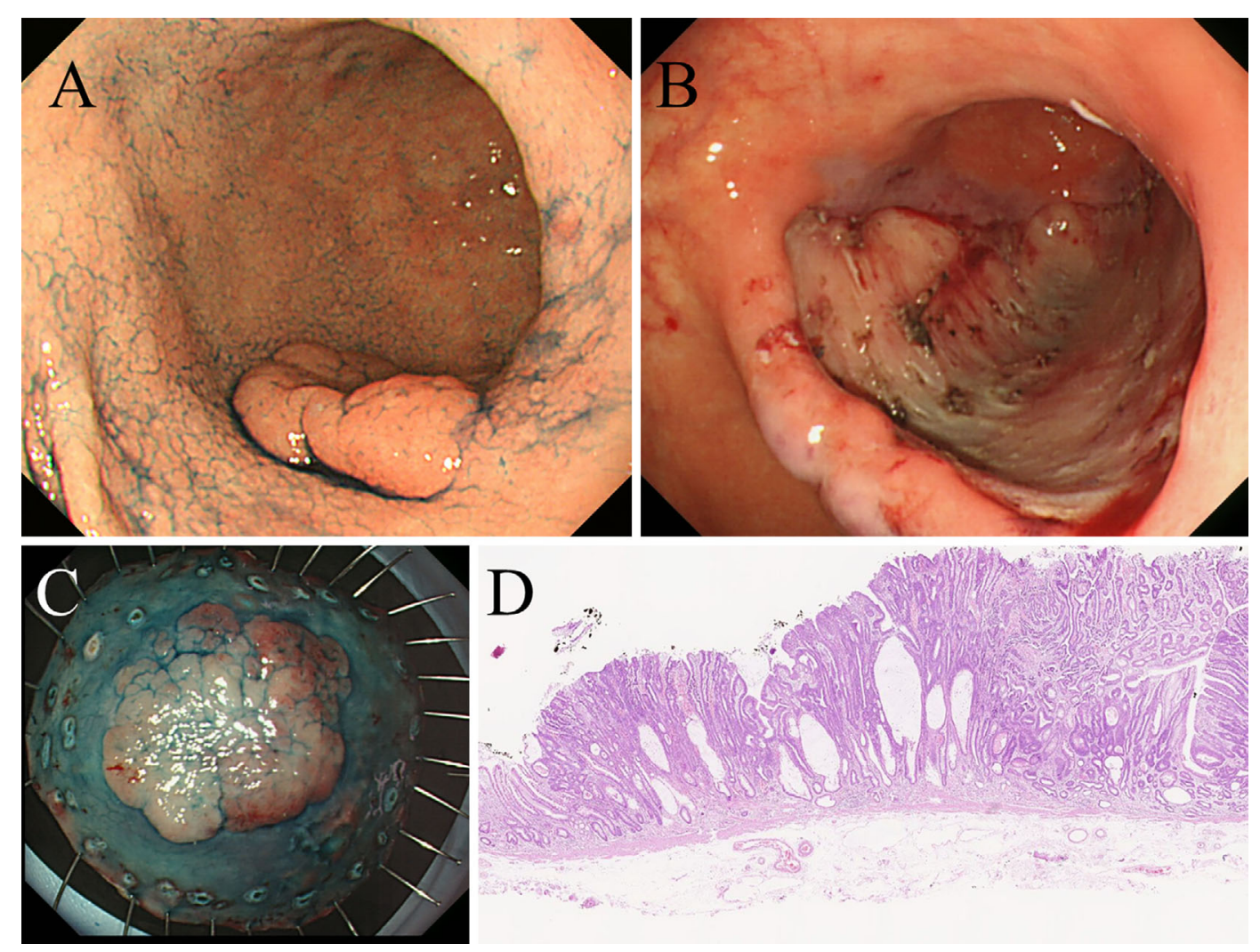

Picture 1.

A 50-year-old man with a history of Helicobacter pylori eradication underwent endoscopic submucosal dissection (ESD) for gastric cancer, which was pathologically diagnosed as well-differentiated tubular adenocarcinoma confined to the mucosa without ulcer or lymphovascular invasion (Picture 1). The horizontal and vertical margins were negative, so curative resection was judged to have been achieved.

Eight months after ESD, esophagogastroduodenoscopy demonstrated a hyperplastic polyp (HP) without malignancy on the ESD scar (Picture 2). Thirty-two months after ESD, however, adenocarcinoma arising from the widely based HP was identified (Picture 3). Because the bottom of the tumor was a benign hyperplastic lesion and because the gastric

${ }^{1}$ Department of Gastroenterology and Hepatology, Kyoto University Graduate School of Medicine, Japan and ${ }^{2}$ Division of Gastroenterology and Hepatology, Digestive Disease Center, Kitano Hospital, Japan

Received: June 2, 2018; Accepted: September 27, 2018; Advance Publication by J-STAGE: December 18, 2018

Correspondence to Dr. Shujiro Yazumi, s-yazumi@kitano-hp.or.jp 


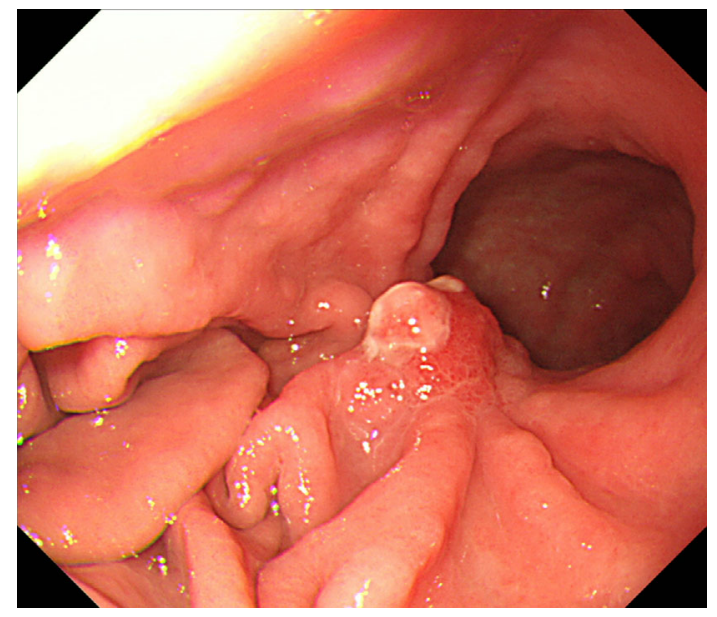

Picture 2.

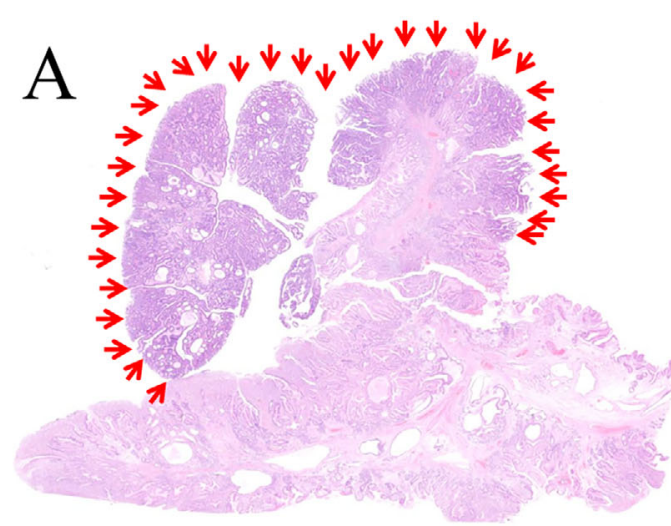

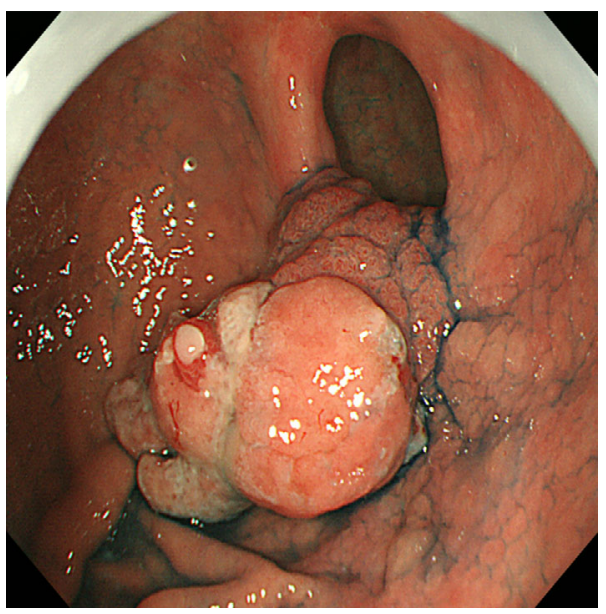

Picture 3.

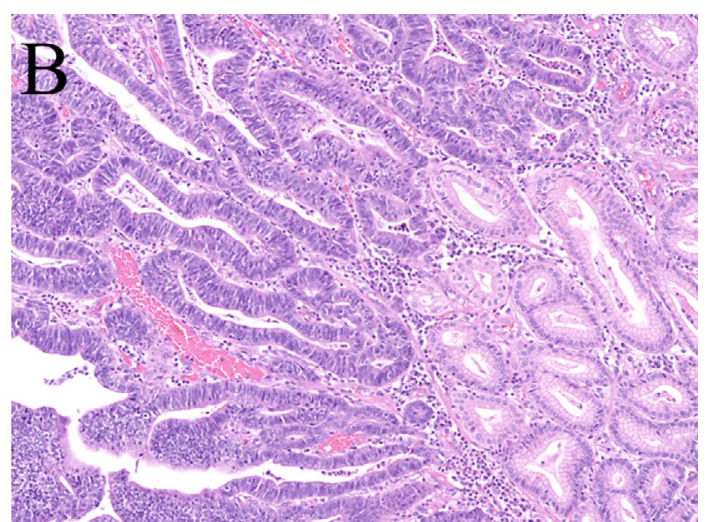

Picture 4.

cancer was small enough to completely resect by endoscopic mucosal resection (EMR), EMR was performed for adenocarcinoma, including a sufficient amount of the HP, which was pathologically diagnosed as well-differentiated tubular adenocarcinoma confined to the mucosa without ulcer or lymphovascular invasion. The horizontal and vertical margins were also negative (Picture 4).

Although extremely rare, we should be aware that a HP on an ESD scar can develop into cancer. Endoscopic resection should be considered in such cases.

The authors state that they have no Conflict of Interest (COI).

The Internal Medicine is an Open Access journal distributed under the Creative Commons Attribution-NonCommercial-NoDerivatives 4.0 International License. To view the details of this license, please visit (https://creativecommons.org/licenses/ by-nc-nd/4.0/).

\section{(C) 2019 The Japanese Society of Internal Medicine} Intern Med 58: 1179-1180, 2019 